January 2021

\title{
Ovarian dynamics and fecundity regulation in blueback herring, Alosa aestivalis, from the Connecticut River, US
}

Foivos Alexandros Mouchlianitis

Aristotle University of Thessaloniki, amouchl@bio.auth.gr

Eric T. Schultz

University of Connecticut - Storrs, eric.schultz@uconn.edu

Thassya C. dos Santos Schmidt

thassya@hi.no

Justin P. Davis

justin.davis@ct.gov

Kostas Ganias

kganias@bio.auth.gr

Follow this and additional works at: https://opencommons.uconn.edu/eeb_articles

Part of the Population Biology Commons

\section{Recommended Citation}

Mouchlianitis, Foivos Alexandros; Schultz, Eric T.; dos Santos Schmidt, Thassya C.; Davis, Justin P.; and Ganias, Kostas, "Ovarian dynamics and fecundity regulation in blueback herring, Alosa aestivalis, from the Connecticut River, US" (2021). EEB Articles. 50.

https://opencommons.uconn.edu/eeb_articles/50 


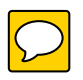

1 Ovarian dynamics and fecundity regulation in blueback herring, Alosa aestivalis, from the Connecticut River, US

4 Foivos A. Mouchlianitis ${ }^{1}$, Eric T. Schultz ${ }^{2}$, Thassya C. dos Santos Schmidt ${ }^{3}$, 5 Justin P. Davis ${ }^{4}$, Kostas Ganias ${ }^{1 *}$

6

$7 \quad{ }^{1}$ School of Biology, Aristotle University of Thessaloniki, Thessaloniki, Greece

8 2Department of Ecology and Evolutionary Biology, University of Connecticut, 9 Storrs, CT, USA

103 Institute of Marine Research, Bergen, Norway

11 4Department of Energy and Environmental Protection, Old Lyme, CT, USA 12

$13{ }^{*}$ Corresponding author: kganias@bio.auth.gr

14

15 Running head: Fecundity of blueback herring in CT River 16 17 18 19 


\section{Abstract}

21 We analyzed ovarian dynamics of anadromous blueback herring, Alosa 22 aestivalis, in Connecticut River with the principal aim of exploring oocyte 23 recruitment and how it shapes the fecundity pattern. We examined the oocyte 24 release strategy and analyzed spawning cyclicity by linking oocyte growth to 25 the degeneration of postovulatory follicles. Females were accordingly classified 26 as pre-spawners, early and late active spawners, and oocyte recruitment 27 intensity was compared among the different spawning phases. Oocyte 28 recruitment occurred continuously and in parallel with spawning activity, a 29 pattern which is diagnostic of indeterminate fecundity. However, both fecundity 30 and oocyte recruitment intensity progressively decreased (tapered) throughout 31 spawning, until the ovary was depleted of vitellogenic oocytes. There was no 32 massive atresia of vitellogenic oocytes at the end of the spawning season, which is atypical of indeterminate spawners. We propose that tapering in oocyte recruitment and fecundity is an adaptation to the high energetic expenditure of the upstream spawning migration.

36

Keywords 


\section{Introduction}

48 Indeterminate spawners recruit oocytes to the secondary growth phase (SG recruitment) in parallel with their spawning activity (Hunter et al., 1989; Witthames et al., 1995). This keeps the total number of SG oocytes in a

51 "dynamic-equilibrium" state (Kjesbu, 2009), wherein SG recruitment 52 counterbalances spawning so that the released oocytes from sequential 53 batches are replenished. This state has been evinced both through extensive 54 analyses of ovarian samples - e.g. Northern anchovy, Engraulis mordax 55 (Hunter and Leong, 1981), European anchovy, E. encrasicolus (Schismenou et al., 2012), and Macedonian shad, Alosa macedonica (Mouchlianitis et al., 2020) - and through simulations of spawning dynamics (Ganias et al., 2015a). Normally, continuous SG recruitment results in a surplus of SG oocytes at the end of spawning period which subsequently fall into massive atresia (Hunter and Macewicz, 1985a; Witthames et al., 1995; Ganias et al., 2014), a process known as "mopping-up" (Wallace et al., 1981; Kjesbu, 2009).

Recent studies have challenged the generality of dynamic-equilibrium and mopping-up in indeterminate spawners. Ganias et al. (2017) report for the Atlantic horse mackerel (Trachurus trachurus) a cessation of SG recruitment and lack of massive atresia in late-season spawners. A similar pattern has been suggested in Gulf menhaden, Brevoortia patronus (Brown-Peterson et al., 2017). Minimizing energetic expenditure by regulating oocyte production might be of adaptive value in fishes that are subject to high energetic costs of reproduction, such as capital breeders or anadromous fishes (McBride et al., 2013).

71 Anadromous alosines (Clupeidae: Alosa spp.) incur substantial energetic losses during their upstream migration towards their spawning grounds (Glebe and Leggett, 1981; Murauskas and Rulifson, 2011; Ganias et al., 2015b). Thus,

74 indeterminate alosines would be suitable models to test for changes in SG 75 recruitment. Broadly speaking, two alternative possibilities are that SG 76 recruitment intensity could either remains constant, or that it could progressively 77 decreases over the spawning season, a pattern we here call tapering. Herein 78 we examine blueback herring $A$. aestivalis $(\mathrm{BBH})$ in the Connecticut River. $\mathrm{BBH}$ 
is an anadromous, economically important alosine that previously provided a valuable fishery for food, bait and fertilizer (Mullen et al., 1986; Kocik, 1998). The species is now regarded as overexploited (Limburg and Waldman, 2009), vulnerable according to the IUCN (NatureServe, 2013) and is listed as a species of concern (NOAA National Marine Fisheries Service, 2009). BBH spawns in freshwater from mid spring to early summer (Loesch and Lund, 1977); the dynamics of its oocyte development remain undescribed.

Our main objective was to analyze ovarian dynamics of $\mathrm{BBH}$ in Connecticut River, with emphasis on how SG recruitment shapes the fecundity pattern. In particular, we focused on SG oocyte recruitment and tested whether intensity is affected by its upstream migration towards the spawning grounds. To do so, females were classified according to their spawning phase based on the characteristics of oocytes and postovulatory follicles. SG recruitment intensity was then compared amongst the different spawning phases and used to determine the equilibrium between oocyte recruitment and spawning. Our results will help improve future estimations of the species' reproductive potential.

(1)

\section{Materials and methods}

\section{Fish collection and processing}

Specimens for this study were collected as part of a project focused on adult $\mathrm{BBH}$ as prey during the spawning season (Davis et al. 2012). To capture BBH on the spawning grounds over the duration of the season, sampling was conducted weekly via electrofishing (Smith-Root Model SR-18 electrofishing boat) from late April to late June 2006 from four sampling sites along the Connecticut River in Northern Connecticut, USA (Table 1; Fig. 1). Sampling sites were located at a significant distance from the river mouth (approximately 60 to $85 \mathrm{~km}$ ). To ensure a broad representation of size-classes, up to 5 fish per $5 \mathrm{~mm}$ size-class were selected, euthanized, placed on ice, and processed within 24 hours. Measurements upon workup included total length, total weight, eviscerated weight $\left(\mathrm{W}_{\mathrm{ev}}\right)$ and gonad weight. Sampling was conducted under the Connecticut State Scientific Collecting Permit SC-05012 and under 
111 University of Connecticut Institutional Animal Care and Use Council Protocol 112 A05-013.

114 Histological analyses

115 Ovarian subsamples of all females $(\mathrm{N}=164)$ were processed histologically 116 using standard procedures ( $2 \mathrm{~mm}$ thick hand-cut cross sections, paraffin 117 embedding, 4- $\mu \mathrm{m}$ sections, hematoxylin/eosin staining). Each ovarian 118 subsample was taken from the middle of the ovary $\dot{\bar{\prime}}$ B based on previous results 119 in several alosines (Loesch and Lund, 1977; Olney et al., 2001; Olney and 120 McBride, 2003; Grice et al., 2014; Sullivan et al., 2019), we considered there 121 were no differences among the anterior, middle and posterior parts of both right 122 and left lobes. Each histological section was digitized into a high-resolution 123 photomicrograph using a slide scanner (NanoZoomer S60, Hamamatsu 124 Photonics, Japan). The photomicrographs enabled identification of distinct 125 developmental stages of SG oocytes (based on Brown-Peterson et al., 2011) 126 and detection of atretic and postovulatory follicles (POFs). We identified the 127 cortical alveolar (CA) stage, the early, secondary and tertiary vitellogenic (VIT128 1, VIT-2, VIT-3) stage, early and late germinal vesicle migration (GVM-1, GVM129 2) stage, and the germinal vesicle break down (GVBD) stage. POFs were 130 staged based on their histomorphological characteristics (Hunter and

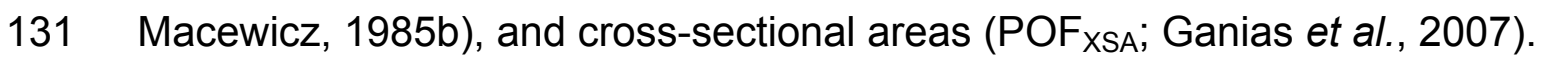

132 The presence of POFs in imminent spawners and/or the co-occurrence of POFs 133 from different daily cohorts (Fig. 2) served as proof of multiple spawning. POFs 134 were also used to classify females into spawning phases:; Wwe identified pre135 spawners (those that had not commenced their spawning activity), active 136 spawners (spawning capable individuals that had spawned at least once during 137 the surveyed season) and spent females (those that had completed their 138 spawning activity). As indicated by Hunter and Macewicz (1985b), pre139 spawners had vitellogenic oocytes and no POFs, active spawners had both 140 vitellogenic oocytes and POFs, and spent females had POFs but no vitellogenic 141 oocytes. 
144 Ovaries from 91 fish were further analyzed through whole-mount procedures.

145 Weighed ovarian subsamples of $\sim 0.1 \mathrm{~g}$ were digitally imaged using a Jenoptik 146 Progress C3 camera mounted on a Euromex NZ 80 stereo microscope. The 147 resulting images were subjected to particle analysis (Thorsen \& Kjesbu, 2001) 148 using ImageJ (https://imagej.nih.gov/ij/) yielding oocyte size frequency 149 distributions (OSFD). By this means we subsequently identified and 150 enumerated oocytes of the advanced mode (AM) and of the subsequent mode 151 (SM), using methods described in Ganias et al. (2010).

152 We estimated the relative fecundity (i.e., number of oocytes $\mathrm{g}^{-1} \mathrm{~W}_{\mathrm{ev}}$ ) of the AM 153 and the SM gravimetrically (Hunter et al., 1985). In order to estimate relative 154 total fecundity (i.e., total number of $S G$ oocytes $\mathrm{g}^{-1}$ of $\mathrm{W}_{\mathrm{ev}} ; \mathrm{RF}_{\mathrm{T}}$ ) it was necessary 155 to distinguish primary growth oocytes (PG) from SG oocytes. Because PG oocytes are translucent and closely attached to each other (Anderson et al. 2000) the whole mount procedure that included oocytes smaller than $200 \mu \mathrm{m}$ needed some extra steps and was thus held in 10 out of the 91 females. The size threshold between $P G$ and SG oocytes was estimated statistically as the mean cutpoint value between the mode of very small oocytes and the SM in 161 these 10 females.

SG recruitment intensity

164 SG recruitment intensity was estimated both through enumerating (a) the very 165 early SG oocytes (i.e. CA stage) in histological specimens, and (b) oocytes with diameters between 200 and $320 \mu \mathrm{m}$ in whole mounts, based on Greer-Walker 167 et al. (1994). In particular, the relative fecundity of CA oocytes (RF $\mathrm{CA}_{\mathrm{A}}$ ) was 168 estimated through the Weibel method (Weibel et al., 1966), implemented on the 169 histological photomicrographs, following the methodology of Emerson et al. 170 (1990). The Weibel method is based on the Delesse principle stating that the 171 fractional volume of a component (here, the CA oocytes) is proportional to its 172 fractional cross-sectional area. The relative fecundity of oocytes between 200 173 and $320 \mu \mathrm{m}\left(\mathrm{RF}_{200-320}\right)$ was estimated gravimetrically from whole-mount 174 analysis. To test whether SG recruitment intensity remained constant 
175 throughout spawning activity, the values of each of these two indices were compared among the different spawning phases.

Statistical analysis

179

All plots and statistical analyses were performed in R 3.5 .2 (www.Rproject.org). Plots were produced by use of $\mathrm{R}$ packages lattice, ggplot2 and ggridges. Cutpoint values for estimating size threshold between PG and SG oocytes were estimated using R package Shazam. Normality was tested by the Shapiro-Wilk test.

\section{Results}

Females were sampled during the spawning season and on the spawning ground. Of the 164 female blueback herrings that were analyzed histologically, $42(26 \%)$ were identified as pre-spawners, 120 (73\%) as active spawners and $2(1 \%)$ as spent (Table 1$)$. Active spawners were caught in almost all sampling dates and sites; two small samples taken early in the season consisted entirely of pre-spawners. Among active spawners, 16\% had two different POF cohorts (Table 1, Fig. 2), indicating that POF degeneration lasted longer than the spawning interval. Most (87.5\%) of the ovaries with two POF cohorts were at the VIT-2 stage and the remainder were at the VIT-3 stage. POFs occurred through the entire range of ovarian development, from early vitellogenesis (VIT2 stage) to final oocyte maturation (GVBD stage, Fig. 3). There was a strong negative relationship between the cross-sectional area of the leading POF cohort, $\mathrm{POF}_{\mathrm{XSA}}$, and the mean diameter of oocytes in the $\mathrm{AM}\left(\mathrm{P}<0.001, \mathrm{R}^{2}=\right.$ 0.71; Fig. 3).

Batches of oocytes to be spawned could be discerned in most females. The AM was clearly discernible in the OSFDs of females from the VIT-3 stage onwards (Fig. 4). The relative fecundity of the AM was considered equivalent to relative batch fecundity $\left(R F_{B}\right)$, i.e. the relative number of oocytes that would have been released during the next spawning episode (see also Ganias et al., 2015a). The subsequent mode (SM) representing the oocyte batch of a second 
upcoming spawning episode was also discernible in >VIT-3 stage females (e.g.,

207 Fig. 5). However, in most cases the SM could not be resolved from smaller oocytes and its relative fecundity $\left(\mathrm{RF}_{\mathrm{SM}}\right)$ could only be estimated by statistically decomposing overlapping modes in the OSFD (see Ganias et al., 2010). The OSFDs of females at the VIT-2 ovarian stage were unimodal (Fig. 4) and we

211 did not estimate $\mathrm{RF}_{\mathrm{B}}$ and $\mathrm{RF}_{\mathrm{SM}}$ for these females.

The OSFDs of the ten females used to estimate the size threshold between PG and SG oocytes showed a clear mode between 4 to $200 \mu \mathrm{m}$ which corresponded to PG oocytes (Fig. 6). The mean cutpoint value between this mode and the SM was $197.3 \mu \mathrm{m}(95 \%$ C.I.: $\pm 40.9 \mu \mathrm{m})$. This value was very 216 close to the $200 \mu \mathrm{m}$ threshold value previously used for other alosines such as 217 the American shad, A. sapidissima (Hyle et al., 2014), and Allis shad, A. alosa 218 (Mouchlianitis et al., 2019). Thus, for generality purposes we also used the $219200 \mu \mathrm{m}$ threshold for distinguishing between PG and SG oocytes.

Batches diminished in size in subsequent spawnings and SG recruitment tapered as the season progressed. Active spawners had significantly $(P<0.05$;

222 two tailed t-test) lower mean $\mathrm{RF}_{\mathrm{T}}\left(469.4\right.$ oocytes $\mathrm{g}^{-1}$ of $\mathrm{W}_{\mathrm{ev}}$ ) and $\mathrm{RF}_{\mathrm{B}}(303.1$ 223 oocytes $\left.\mathrm{g}^{-1}\right)$ than pre-spawners $\left(\mathrm{RF}_{\mathrm{T}}=917.2 \mathrm{~g}^{-1} ; \mathrm{RF}_{\mathrm{B}}=519.6\right.$ oocytes $\left.\mathrm{g}^{-1}\right)$. The $224 \mathrm{RF}_{\mathrm{SM}}$ of imminent pre-spawners was intermediate (mean 396 oocytes $\mathrm{g}^{-1}$ ). We accordingly classified active spawners as early, i.e. those that had only spawned once during the current season, and late, i.e. those that had spawned at least twice. Active spawners with $\mathrm{RF}_{\mathrm{AM}} \geq 396$ oocytes $\mathrm{g}^{-1}$ were classified as early spawners; all females with two POF cohorts or $\mathrm{RF}_{\mathrm{AM}}<396$ oocytes $\mathrm{g}^{-1}$ were classified as late spawners. Late spawners exhibited significantly lower

$230 \mathrm{RF}_{200-320}$ values than pre-spawners and early active spawners $(P<0.05$; least 231 significant difference, 95\% confidence level; Fig. 7a). Similarly, late spawners 232 displayed significantly lower $\mathrm{RF}_{\mathrm{CA}}$ values than pre-spawners and early active 233 spawners $(P<0.001$; least significant difference, 95\% confidence level; Fig. $2347 b)$. 
237 Multiple spawning shown here for $\mathrm{BBH}$ is characteristic of anadromous 238 alosines. Multiple spawning of $\mathrm{BBH}$ in the Connecticut River was indicated by 239 the presence of POFs in imminent spawners and the co-occurrence of two 240 different POF cohorts in several females. The production and the degeneration 241 of POFs was in phase with the spawning cycle: very recent spawners with new 242 and large POFs were at the beginning of vitellogenesis; then, POFs gradually 243 shrunk as the ovary developed and they finally reached a very small size just 244 before the next spawning episode. This pattern explained the co-existence of 245 POFs from two different cohorts, especially in females at early vitellogenesis, 246 i.e. the beginning of the new spawning cycle. Other anadromous alosines 247 shown to be multiple spawners include Alewife A. pseudoharengus (Ganias et 248 al., 2015b), American Shad (Olney et al., 2001; McBride et al., 2016), Hickory 249 Shad A. mediocris (Murauskas and Rulifson, 2011), Alabama Shad A. 250 alabamae (Mettee and O'Neil, 2003) and Twaite Shad A. fallax fallax (Pina et 251 al., 2003), as well as the landlocked Macedonian Shad A. macedonica 252 (Mouchlianitis et al., 2020).

$253 \mathrm{BBH}$ displayed indeterminate fecundity. Oocyte recruitment continued to the 254 end of the spawning period as indicated by the presence of early SG oocytes 255 both in late active spawners and spent females. Indeterminate fecundity has 256 been documented for several anadromous alosines, e.g., Hickory Shad 257 (Murauskas and Rulifson, 2011), American Shad (Hyle et al., 2014), and 258 Alewife (Ganias et al., 2015b) and the landlocked Macedonian Shad 259 (Mouchlianitis et al., 2020). We interpret indeterminate fecundity as a strategy 260 conferring flexibility of energy allocation in the face of migration costs; in 261 contrast to determinate fecundity which designates the full complement of 262 oocytes in advance, the indeterminate strategy commits energy to reproduction 263 as spawning continues to be possible. Given that multiple spawning and 264 indeterminate fecundity require an ongoing energetic investment into oocyte 265 production (Lowerre-Barbieri et al., 1998; McBride et al., 2013), we examined 266 whether and how BBH adjusts its fecundity pattern and SG recruitment strategy 267 to counterbalance the costs of its spawning run.

268 In most indeterminate spawners, oocytes from each spawning are replenished 269 by newly recruited SG oocytes in dynamic equilibrium (Kjesbu, 2009). As a 
270 result, continuous SG recruitment leads to a surplus of SG oocytes that will not

271 be spawned at the end of the individual spawning period; these oocytes fall into 272 massive atresia (Hunter and Macewicz, 1985b; Greer-Walker et al., 1994;

273 Ganias et al., 2014) a process known as mopping-up (Wallace et al., 1981; 274 Kjesbu, 2009). Mopping-up will only recover a portion of the energy that was 275 invested in oocytes, representing a potentially expensive inefficiency. Some 276 species, such as the Atlantic horse mackerel (Ganias et al., 2017) and the Gulf 277 menhaden (Brown-Peterson et al., 2017) modulate or avoid mopping-up 278 through a cessation of SG recruitment well before the end of spawning. In 279 contrast, $\mathrm{BBH}$ in the Connecticut River, even though they continue to recruit 280 SG oocytes throughout the spawning period, avoid massive atresia by reducing 281 the intensity of SG recruitment as spawning progresses.

282 By tapering SG recruitment, BBH evidently maximize the efficiency of continued 283 energetic investment in spawning through the season. Tapering in SG recruitment reduces batch fecundity in successive rounds of spawning; the advanced mode always had more oocytes than the subsequent batch(es), both in pre-spawners and in active spawners. Consequently, as batch fecundity decreased from one spawning event to the next, the total number of SG oocytes (i.e. total fecundity) also decreased, and finally, spent females showed no 289 vitellogenic oocytes, avoided massive atresia, and only contained primary growth oocytes and a few CA oocytes. Ovaries of spent female BBH collected 291 from the same location in May 2018 (authors unpublished data) similarly lacked massive atresia. All females, including the spent ones, contained primary growth oocytes in their ovaries indicating the potential to migrate and reproduce in the next spawning season(s). Despite this potential, repeat spawners in Connecticut River female BBH are not common (15-30\% $\div$ : Davis et al., 2009), indicating low adult survivorship and potentially poor population resilience.

297 Tapering in SG recruitment and fecundity modulates energy allocated to oocyte 298 production, perhaps to better meet the high energetic demands of the riverine 299 phase of its reproductive cycle, which involves upstream migration, spawning 300 and potentially prolonged residence on the spawning ground or repeated 301 rounds of migratory return to the spawning ground. Other populations of $\mathrm{BBH}$ 302 (Simonin et al., 2007; McBride et al., 2010) incur substantial energetic losses 
303 during long upstream migrations up to $\sim 400 \mathrm{~km}$. The impact of such long 304 migrations on energy available for reproduction has not yet been assessed. 305 Given the significantly shorter upstream migration distance for the $\mathrm{BBH}$ in 306 Connecticut River and thus, the smaller energetic cost of its spawning run we 307 predict that other populations should deploy similar strategy of SG recruitment 308 and fecundity regulation.

309 We conclude that BBH maximizes efficiency of investment in reproduction over 310 the spawning season through tapering of SG recruitment, a pattern which - to 311 our knowledge - has never been shown for a fish species. Our study offers new 312 insight into the ovarian dynamics of indeterminate spawners. A steady balance 313 between oocyte recruitment and release, followed by mopping-up, was initially 314 described for the Northern anchovy Engraulis mordax (Hunter and Leong, 315 1981) and has thereafter been adopted as a universal criterion of indeterminate 316 fecundity in several fish reproduction studies and reviews (e.g. Murua and 317 Saborido-Rey, 2003; Armstrong and Witthames, 2012). It is now clear that 318 indeterminate spawners may deploy alternative strategies and avoid mopping319 up, e.g. through ceasing SG recruitment at late-season spawners, or, as shown 320 in this paper, through tapering SG recruitment and fecundity until the ovary is 321 depleted of its stock of vitellogenic oocytes.

\section{Acknowledgments}

324 The authors are grateful to the Connecticut Department of Energy and 325 Environmental Protection, the Connecticut River Coordinator's Office of the US 326 Fish and Wildlife Service, and the Center for Environmental Science and 327 Engineering of the University of Connecticut for their financial, technical and 328 logistical support during sampling. We are also grateful to J. Achilli, J. Divino, 329 K. Gherard, S. Hovorka, S. Ruiz, B. Tate and A. Wasley for assistance with field 330 and laboratory work. The histological sections were scanned at the Institute of 331 Marine Research at Bergen, Norway under the supervision of O.S. Kjesbu and 332 A. Thorsen. The research work was supported by the Hellenic Foundation for 333 Research and Innovation (HFRI) and the General Secretariat for Research and 
334 Technology (GSRT), under the HFRI PhD Fellowship grant attributed to F.A. 335 Mouchlianitis with grant agreement No 493584.

336 
337

Data Availability Statement

338

339 There is no data to share

340 


\section{References}

342

343

Armstrong, M. J., and Witthames, P. R. 2012. Developments in understanding of fecundity of fish stocks in relation to egg production methods for estimating spawning stock biomass. Fisheries Research, 117-118: 35-47.

Brown-Peterson, N. J., Wyanski, D. M., Saborido-Rey, F., Macewicz, B. J., and Lowerre-Barbieri, S. K. 2011. A Standardized Terminology for Describing Reproductive Development in Fishes. Marine and Coastal Fisheries, 3: 52-70.

Brown-Peterson, N. J., Leaf, R. T., Schueller, A. M., and Andres, M. J. 2017. Reproductive dynamics of Gulf menhaden (Brevoortia patronus) in the northern Gulf of Mexico: effects on stock assessments. Fishery Bulletin, 115: 284-299.

Davis, J. P., Schultz, E. T., and Vokoun, J. C. 2009. Assessment of River Herring and Striped Bass in the Connecticut River: Abundance, Population Structure, and Predator/Prey Interactions. Final Report submitted to Connecticut Department of Environmental Protection. Storrs, CT. http://digitalcommons.uconn.edu/eeb_articles/26.

Davis, J. P., Schultz, E. T. , and Vokoun, J. C. 2012. Striped Bass consumption of Blueback Herring during vernal riverine migrations: Does relaxing harvest restrictions on a predator help conserve a prey species of concern? Marine and Coastal Fisheries, 4:239-251

Emerson, L. S., Walker, M. G., and Witthames, P. R. 1990. A stereological method for estimating fish fecundity. Journal of Fish Biology, 36: 721-730.

Ganias, K., Nunes, C., and Stratoudakis, Y. 2007. Degeneration of sardine (Sardina pilchardus) postovulatory follicles: structural changes and factors affecting resorption. Fishery Bulletin, 105: 131-139.

Ganias, K., Rakka, M., Vavalidis, T., and Nunes, C. 2010. Measuring batch fecundity using automated particle counting. Fisheries Research, 106: 570-574.

Ganias, K., Somarakis, S., and Nunes, C. 2014. Reproductive Potential. In 

Biology and Ecology of Sardines and Anchovies, pp. 79-121. CRC Press, Boca Raton, FL. Ed. by K. Ganias.

Ganias, K., Lowerre-barbieri, S. K., and Cooper, W. 2015a. Understanding the determinate - indeterminate fecundity dichotomy in fish populations using a temperature dependent oocyte growth model. Journal of Sea Research, 96: 1-10.

Ganias, K., Divino, J. N., Gherard, K. E., Davis, J. P., Mouchlianitis, F., and Schultz, E. T. 2015b. A reappraisal of reproduction in anadromous alewives: determinate versus indeterminate fecundity, batch size, and batch number. Transactions of the American Fisheries Society, 144: 11431158.

Ganias, K., Mouchlianitis, F. A., Nunes, C., Costa, A. M., and Angélico, M. M. 2017. A reassessment of the fecundity type of Atlantic horse mackerel (Trachurus trachurus) in Atlantic Iberian waters (ICES division IXa) shows that indeterminate spawners can cease recruiting oocytes during their spawning season. ICES Journal of Marine Science, 74: 31-40.

Glebe, B. D., and Leggett, W. C. 1981. Temporal, Intra-population Differences in Energy Allocation and Use by American Shad (Alosa sapidissima) During the Spawning Migration. Canadian Journal of Fisheries and Aquatic Sciences, 38: 795-805.

Greer-Walker, M., Witthames, P. R., and Bautista De Los Santos, J. I. 1994. Is the fecundity of the Atlantic mackerel (Scomber scombrus: scombridae) determinate? Sarsia, 79: 13-26.

Grice, H., Patterson, L., Giangiacomo, C., Bowen, M., and Davin, B. 2014. Potential spawning strategy and fecundity of alabama shad (Alosa alabamae) from the Apalachicola River, Florida. Georgia Journal of Science, 72: 94-102.

Hunter, J. R., and Leong, R. J. H. 1981. The spawning energetics of female northern anchovy Engraulis mordax. Fishery Bulletin, 79: 215-230.

Hunter, J. R., and Macewicz, B. 1985a. Rates of atresia in the ovary of captive 
and wild northern anchovy, Engraulis mordax. Fishery Bulletin, 83: 119136.

Hunter, J. R., and Macewicz, B. J. 1985b. Measurement of spawning frequency in multiple spawning fishes. In An egg production method for estimating spawning biomass of pelagic fish: application to the northern anchovy, Engraulis mordax.NOAA Technical Report NMFS 36, pp. 79-94. Ed. by R. Lasker.

Hunter, J. R., Lo, N. C. H., and Leong, R. J. H. 1985. Batch fecundity in multiple spawning fishes. In An egg production method for estimating spawning biomass of pelagic fish: application to the northern anchovy, Engraulis mordax. NOAA Technical Report NMFS 36, pp. 67-77. Ed. by R. Lasker.

Hunter, J. R., Macewicz, B. J., and Kimbrell, C. A. 1989. Fecundity and Other Aspects of the Reproduction of Sablefish, Anoplopoma fimbria, in Central California Waters. California Cooperative Oceanic Fisheries Investigations Reports, 30: 61-72.

Hyle, A. R., McBride, R. S., and Olney, J. E. 2014. Determinate Versus Indeterminate Fecundity in American Shad, an Anadromous Clupeid. Transactions of the American Fisheries Society, 143: 618-633.

Kjesbu, O. S. 2009. Applied fish reproductive biology: contribution of individual reproductive potential to recruitment and fisheries management. In Fish reproductive biology: implications for assessment and management, pp. 293-332. Wiley-Blackwell Science Ltd., Oxford, U.K. Ed. by T. Jakobsen, M. J. Fogarty, B. A. Megrey, and E. Moksness.

Kocik J. 1998. River herring. In Status of Fishery Resources off the Northeastern US for 1998 NOAA Tech Memo NMFS NE 115. Ed. by S. H. Clark.

Limburg, K. E., and Waldman, J. R. 2009. Dramatic Declines in North Atlantic Diadromous Fishes. Bioscience, 59: 955-965.

Loesch, J. G., and Lund, W. A. 1977. A Contribution to the Life History of the Blueback Herring, Alosa aestivalis. Transactions of the American Fisheries 
Society, 106: 583-589.

432

Lowerre-Barbieri, S. K., Lowerre, J. M., and Barbieri, L. R. 1998. Multiple spawning and the dynamics of fish populations: inferences from an individual-based simulation model. Canadian Journal of Fisheries and Aquatic Sciences, 55: 2244-2254.

McBride, R. S., Harris, J. E., Hyle, A. R., and Holder, J. C. 2010. The Spawning Run of Blueback Herring in the St. Johns River, Florida. Transactions Of The American Fisheries Society, 139: 598-609.

McBride, R. S., Somarakis, S., Fitzhugh, G. R., Albert, A., Yaragina, N. A., Wuenschel, M. J., Alonso-Fernández, A., et al. 2013. Energy acquisition and allocation to egg production in relation to fish reproductive strategies. Fish and Fisheries, 16: 23-57.

McBride, R. S., Ferreri, R., Towle, E. K., Boucher, J. M., and Basilone, G. 2016. Yolked oocyte dynamics support agreement between determinate- and indeterminate-method estimates of annual fecundity for a northeastern United States population of American shad. PLoS ONE, 11: e0164203. https://doi.org/10.1371/journal.pone.0164203.

Mettee, M. F., and O'Neil, P. E. 2003. Status of Alabama shad and skipjack herring in Gulf of Mexico drainages. In Biodiversity, status and conservation of the world's shad. American Fisheries Society Symposium 35, Bethesda, Maryland, pp. 157-170. Ed. by K. E. Limburg, and J. R. Waldman.

Mouchlianitis, F. A., Belo, A. F., Vieira, A. R., Quintella, B. R., Almeida, P. R., and Ganias, K. 2019. Primary and secondary oocyte growth dynamics in anadromous semelparous Allis shad Alosa alosa. Journal of Fish Biology, 95: 1447-1456.

Mouchlianitis, F. A., Minos, G., and Ganias, K. 2020. Timing of oocyte recruitment within the ovulatory cycle of Macedonian shad, Alosa macedonica, a batch spawning fish with indeterminate fecundity. Theriogenology, 146: 31-38. 
Mullen, D. M., Fay, C. W., and Moring J. R. 1986. Species profiles: life histories and environmental requirements of coastal fishes and invertebrates (North Atlantic): alewife/blueback herring. U. S. Fish and Wildlife Service Biological Reports 82 (11.56). U. S. Army Corps of Engineers, TR EL-824.

Murauskas, J. G., and Rulifson, R. A. 2011. Reproductive development and related observations during the spawning migration of hickory shad. Transactions of the American Fisheries Society, 140: 1035-1048.

Murua, H., and Saborido-Rey, F. 2003. Female reproductive strategies of marine fish species of the North Atlantic. Journal of Northwest Atlantic Fishery Science, 33: 23-31.

NatureServe 2013. Alosa aestivalis. The IUCN Red List of Threatened Species 2013: e.T201946A2730890. https://dx.doi.org/10.2305/IUCN.UK.20131.RLTS.T201946A2730890.en. (Downloaded on 15 January 2020)

NOAA National Marine Fisheries Service 2009. Species of Concern: River Herring (Alewife and Blueback Herring). NOAA NMFS, Office of Protected

Olney, J. E., and McBride, R. S. 2003. Intraspecific variation in batch fecundity of American shad: revisiting the paradigm of reciprocal latitudinal trends in

Olney, J. E., Denny, S. C., and Hoenig, J. M. 2001. Criteria for determining 484 maturity stage in female American shad, Alosa sapidissima, and a proposed reproductive cycle. Bulletin Francais De La Peche Et De La Pisciculture, 362/363: 881-901.

Pina, T., Esteves, E., and Andrade, J. P. 2003. Gross and histological observations of ovarian development in twaite shad, Alosa fallax fallax, from the Rivers Mira and Guadiana (Portugal). Scientia Marina, 67: 313322. 
491 Schismenou, E., Somarakis, S., Thorsen, A., and Kjesbu, O. S. 2012. Dynamics 492 of de novo vitellogenesis in fish with indeterminate fecundity: an application of oocyte packing density theory to European anchovy, Engraulis encrasicolus. Marine Biology, 159: 757-768.

Simonin, P. W., Limburg, K. E., and Machut, L. S. 2007. Bridging the Energy Gap: Anadromous Blueback Herring Feeding in the Hudson and Mohawk Rivers, New York. Transactions of the American Fisheries Society, 136:

Sullivan, K. M., Bailey, M. M., Berlinsky, D. L. 2019. Digital image analysis as a technique for Alewife fecundity estimation in a New Hampshire River. North American Journal of Fisheries Management, 39: 353-361.

Thorsen, A., and Kjesbu, O. S. 2001. A rapid method for estimation of oocyte size and potential fecundity in Atlantic cod using a computer-aided particle analysis system. Journal of Sea Research, 46: 295-308.

Wallace, R. A., and Selman, K. 1981. Cellular and dynamic aspects of oocyte growth in teleosts. American Zoologist, 21: 325-343.

Weibel, E. R., Kistler, G. S., and Scherle, W. F. 1966. Practical stereological methods for morphometric cytology. Journal of Cell Biology, 30: 23-38.

Witthames, P. R., and Greer-Walker, M. 1995. Determinacy of fecundity and oocyte atresia in sole (Solea solea) from the Channel, the North Sea and the irish Sea. Aquatic Living Resources, 8: 91-109. 
Figure legends

517 Figure 1 Sampling sites in the Connecticut River, State of Connecticut, USA:

518 Wethersfield (41043'31.31" N, 72³8'58.73" W), Farmington River 519 (41050'10.06" N, 72³8'9.41" W), Windsor Locks (41053'49.60" N, 72037'17.53”'W), Enfield (41059'29.72” N, 72॰36'13.15” W).

521 Figure 2 Photomicrograph of an ovarian histological section (hematoxylin/eosin

522 staining) showing two postovulatory follicles (POFs) originated from two 523 sequential daily spawning events (newest and previous POF cohort).

524 Figure 3 Cross-sectional area of the biggest postovulatory follicle (POF $\left.\mathrm{XSA}_{\mathrm{A}}\right)$ in 525 the histological section of active spawners versus the mean diameter of oocytes 526 at the most advanced developmental stage $\left(O D_{A M}\right)$. Differing symbols 527 represent ovarian developmental stage, i.e., developmental stage of the most 528 advanced oocytes in the ovary. VIT-2 = secondary vitellogenic, VIT-3 = tertiary 529 vitellogenic, GVM-1 = early germinal vesicle migration, GVM-2 = late germinal 530 vesicle migration, GVBD = germinal vesicle breakdown stage. Line represents 531 the fitted exponential regression.

532 Figure 4 Oocyte size frequency distributions (OSFD) of secondary growth 533 oocytes in whole mount preparations of: (a) pre-spawners and (b) active 534 spawners. Color of OSFD represents the ovarian developmental stage, i.e. the 535 developmental stage of the most advanced oocytes in the ovary. OSFDs are 536 displayed in order of increasing (bottom to top) mean oocyte diameter of the 537 most advanced oocytes. Legend abbreviations for developmental stage are 538 described in caption of Fig. 34 .

539 Figure 5 Oocyte size frequency distribution of secondary growth oocytes of a 540 single female with ovary in VIT-3 stage. Oocytes are divided into fine $(25 \mu \mathrm{m})$ 541 diameter classes to resolve modes. The advanced mode (AM) is 542 distinguishable whilst the subsequent mode (SM4) is overlapping with 543 remaining oocyte modes.

544 Figure 6 Combined oocyte size frequency distribution of all oocytes from the 545 ten females that were used to estimate the mean size threshold value (solid red 
546 line) between primary growth (PG) and secondary growth (SG) oocytes. Dotted

547 lines correcpond to $95 \%$ confidence intervals.

548 Figure 7 Box and whisker plots of log transformed values of: (a) relative

549 fecundity of oocytes with diameter between 200 and $320 \mu \mathrm{m}\left(\mathrm{RF}_{200-320}\right)$, and (b)

550 relative fecundity of the cortical alveolar oocytes $\left(\mathrm{RF}_{\mathrm{CA}}\right)$, by spawning phase.

551 The heavy central line of each box represents the median, the top and bottom

552 lines extend from the lower to the upper quartile and the top and bottom

553 whiskers extend to the lowest and highest values within the $1.5 \mathrm{x}$ the

554 interquartile range. Observations outside the $1.5 \mathrm{x}$ the interquartile range

555 represent the extreme values and are represented as open dots. Statistically

556 significant pairwise comparisons of mean values are shown with asterisk(s) ("*"

557 for $\mathrm{P}<0.05$, “**” for $\mathrm{P}<0.001$ ). 


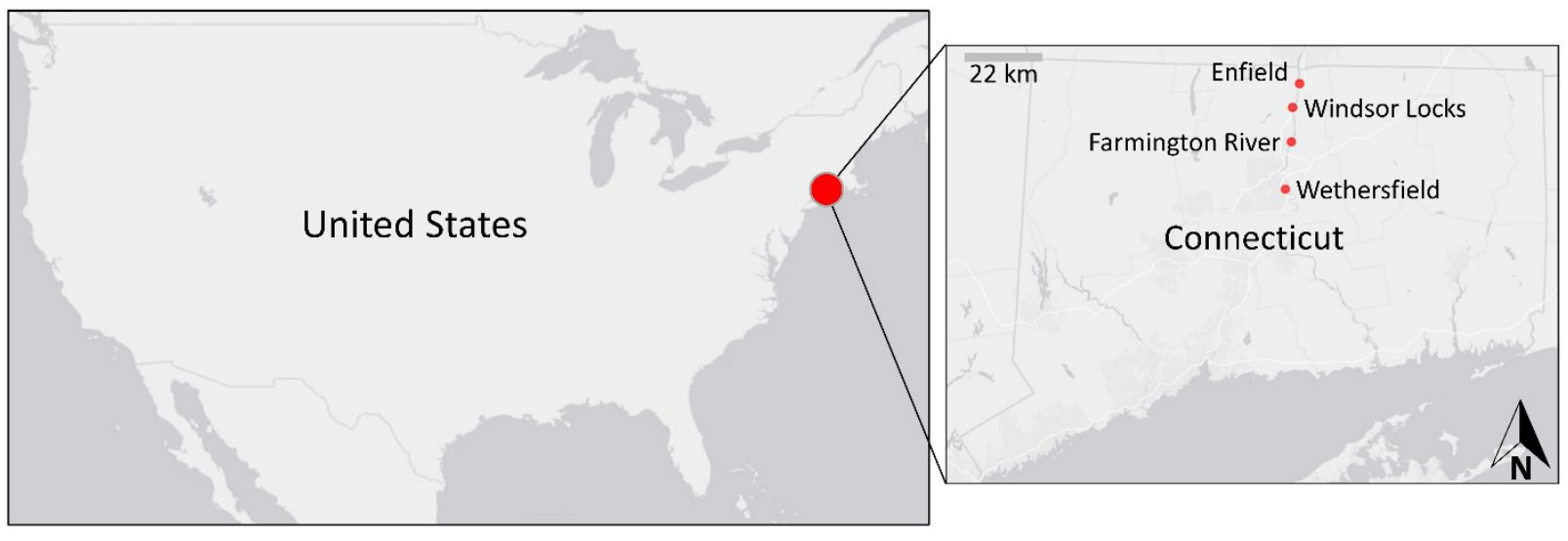

561

562

Figure 1

563

564

565

566

567

568

569

570

571

572 


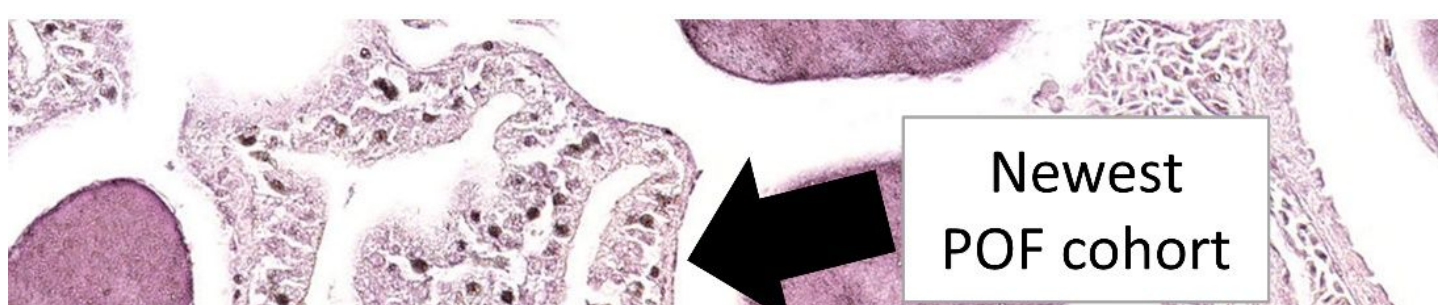

15.
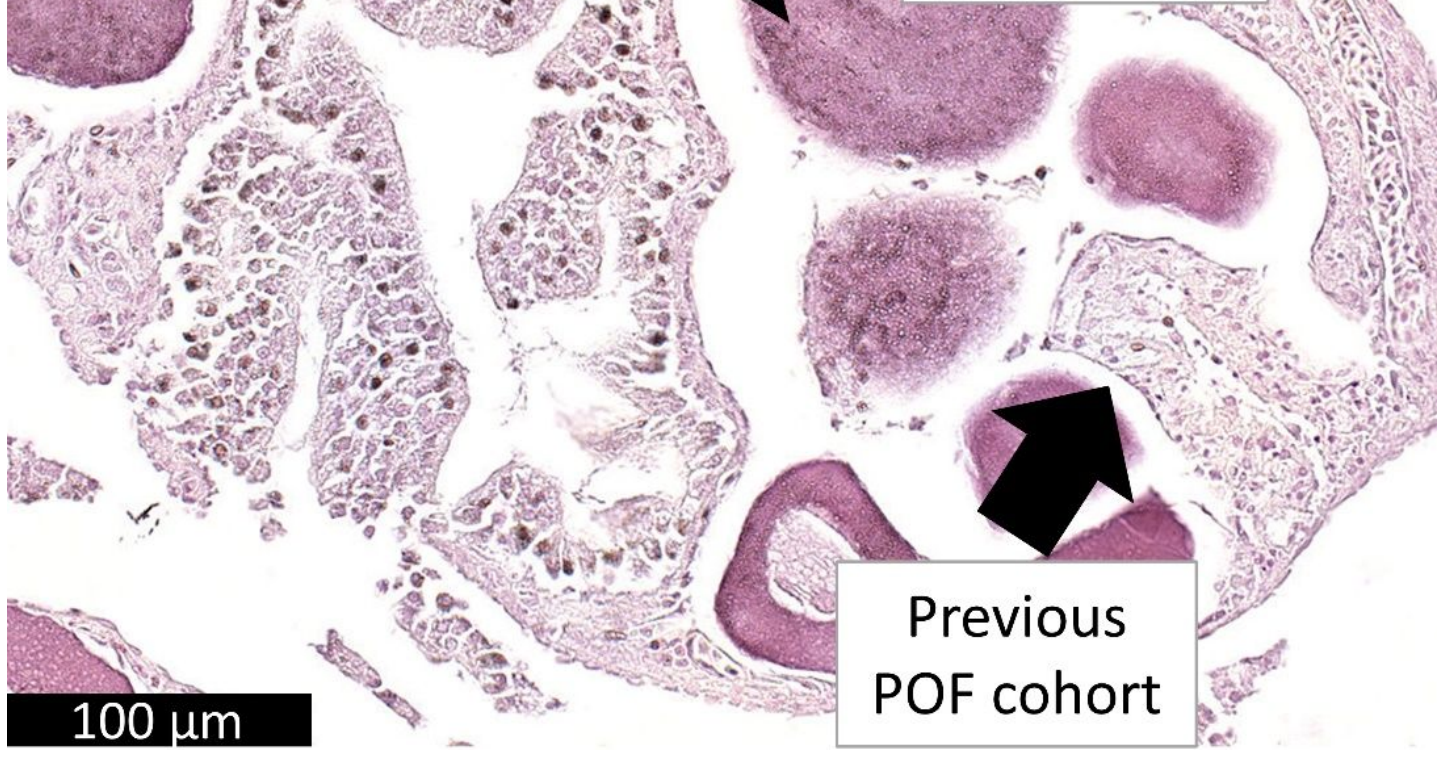

\section{4}


580

581

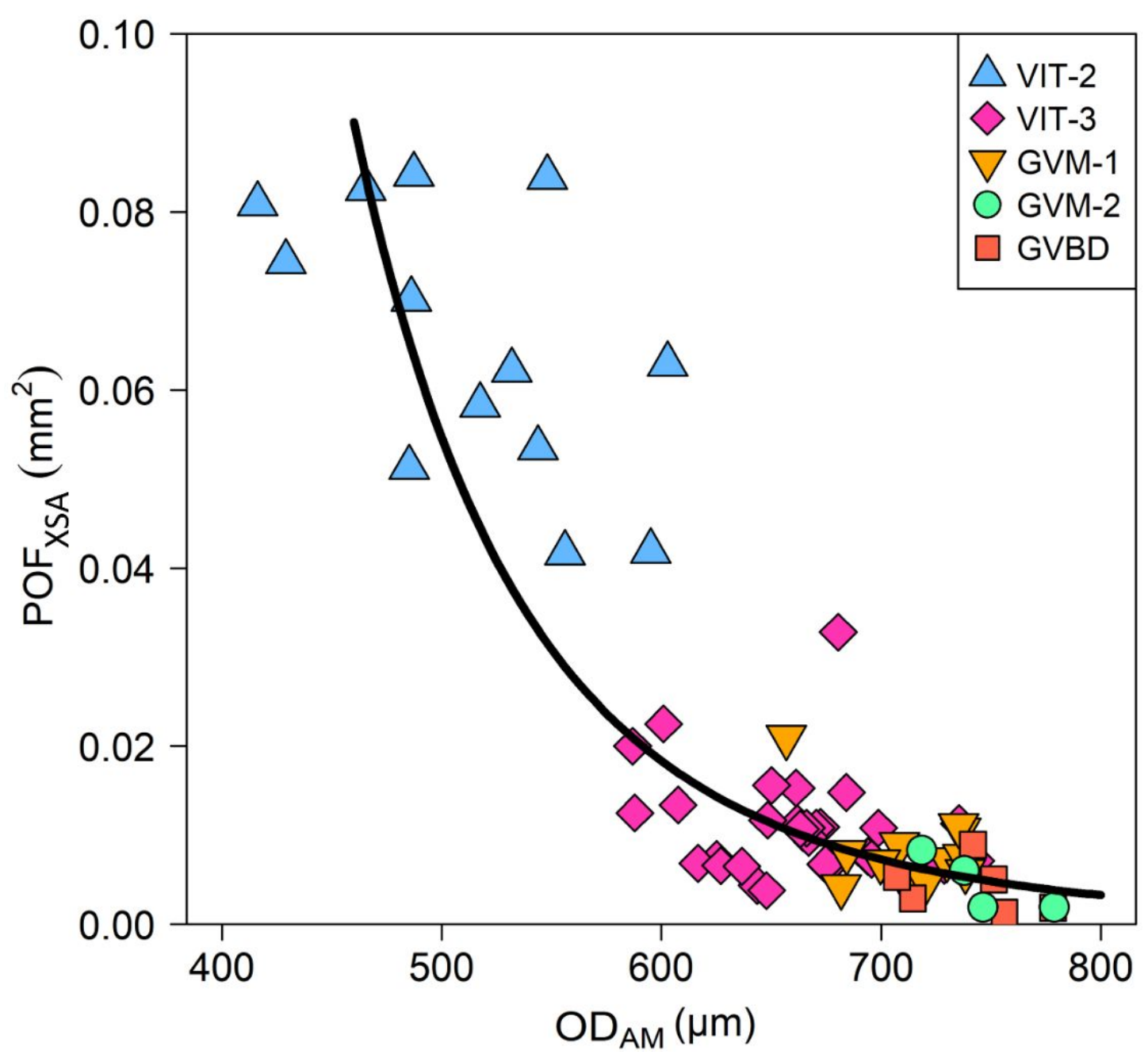

582

583

Figure 3

584

585

586 
(a)

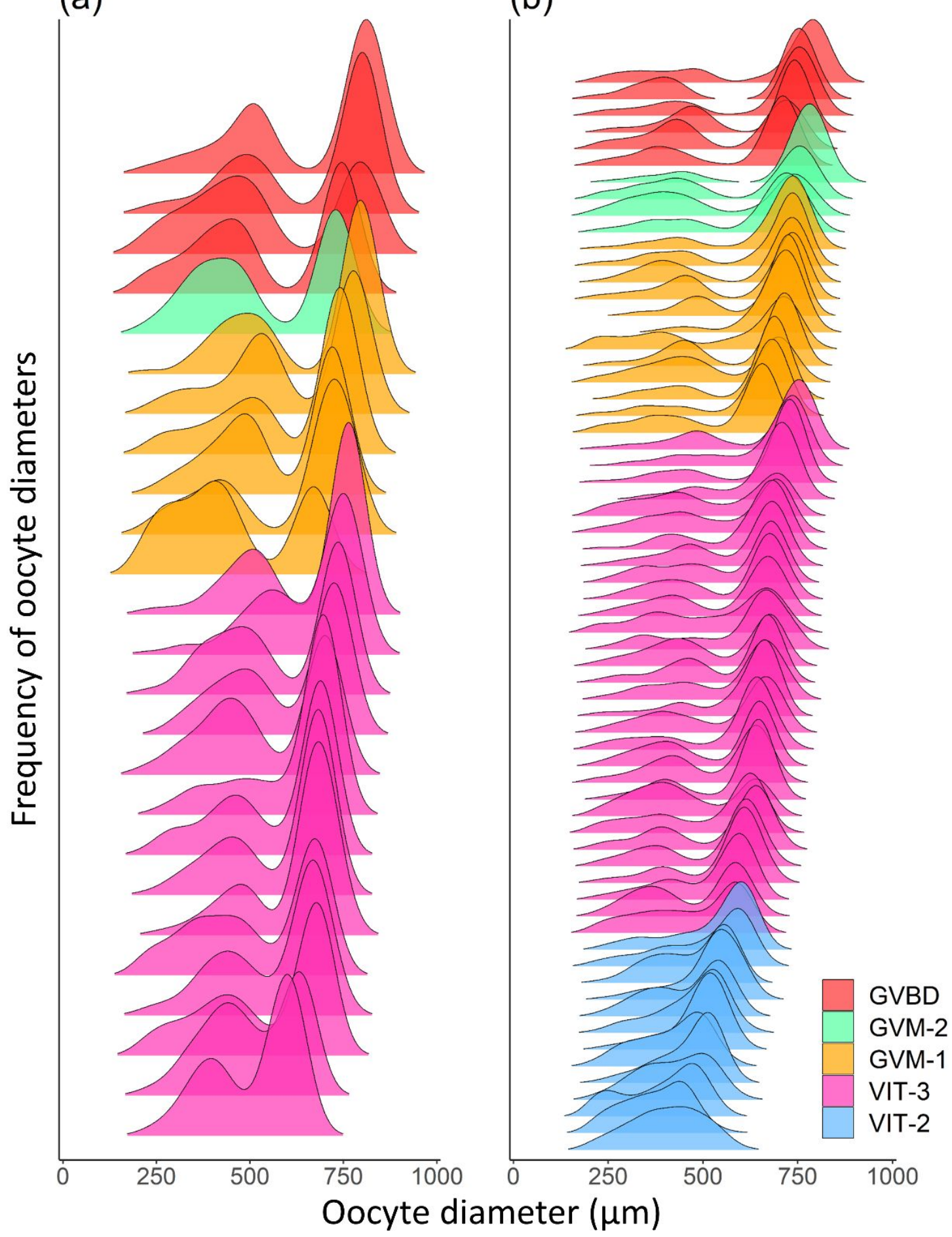


590

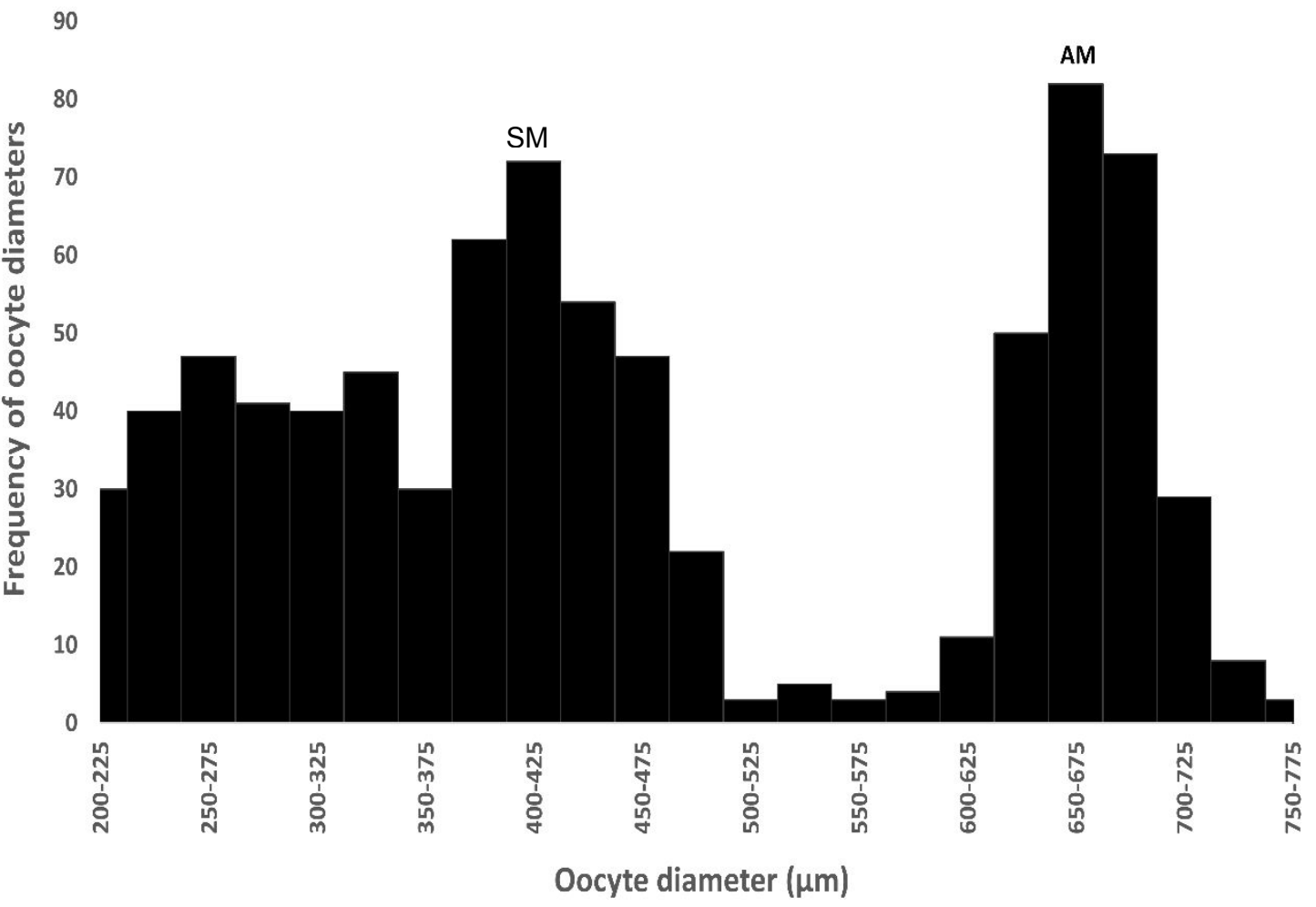

592

593

Figure 5

594 


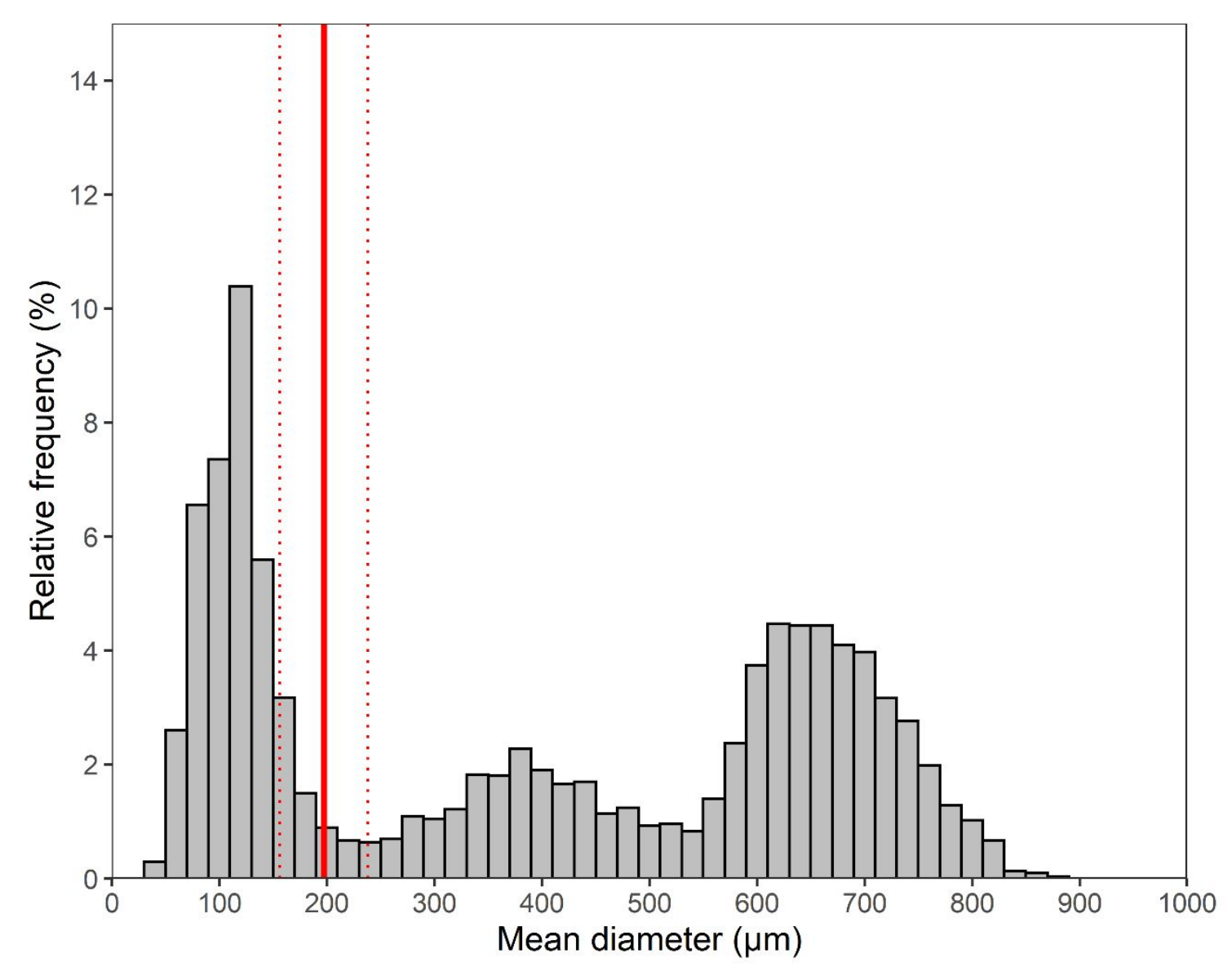

595

596

597

Figure 6

598

599 
600

601
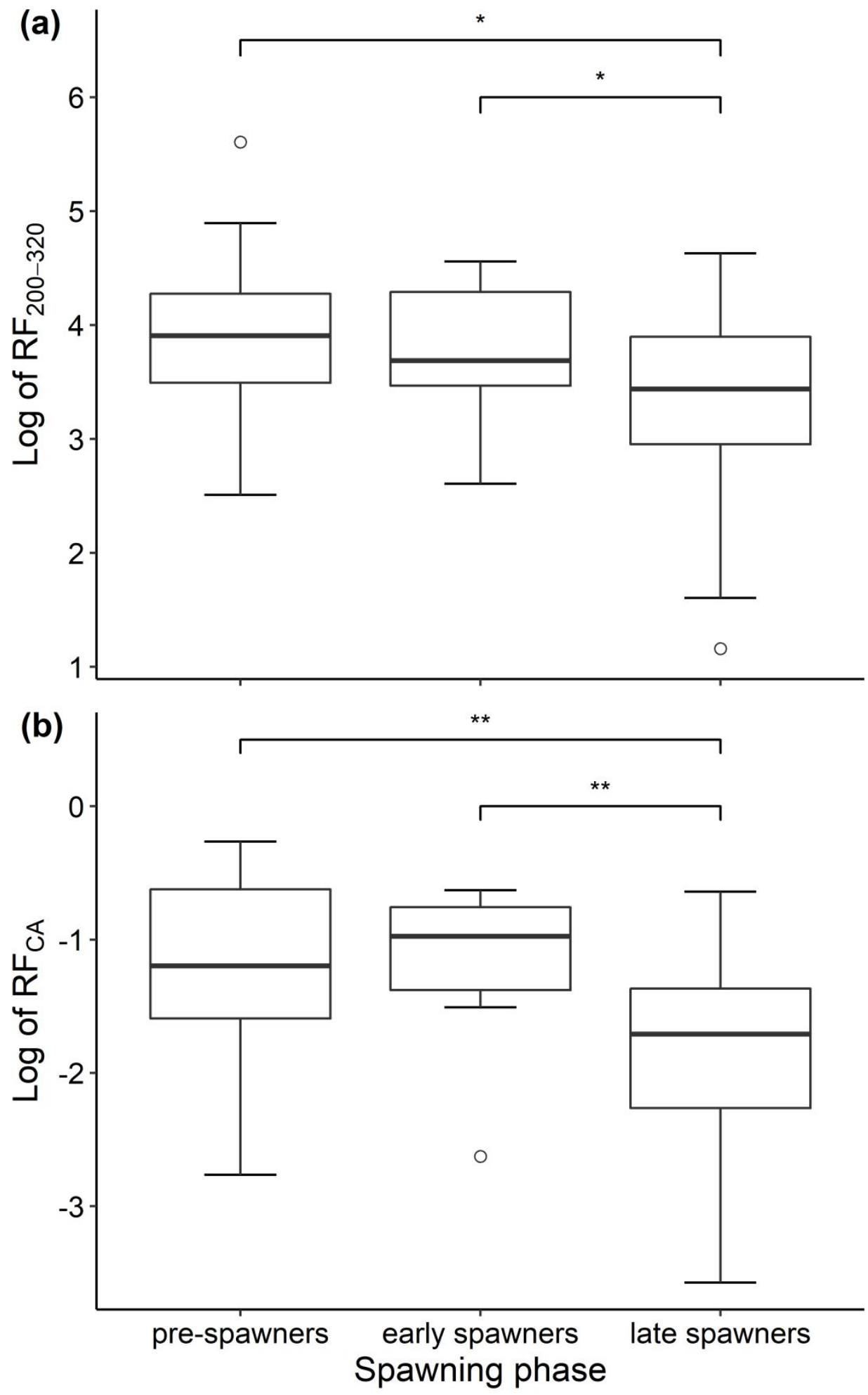

602 Spawning phase

603

Figure 7

604 
605 Table 1. Number of females analyzed histologically $\left(\mathrm{N}_{\text {his }}\right)$ and through whole606 mount analysis $\left(\mathrm{N}_{\mathrm{wm}}\right)$ and total length range ( $\mathrm{L}$ in $\left.\mathrm{mm}\right)$ per sampling date and 607 sampling site. WF = Wethersfield, FR = Farmington River, WL = Windsor Locks, $608 \mathrm{EF}=$ Enfield. The percentage of fish per spawning phase (pre-spawners, active 609 spawners, spent females) and the percentages of fish having one postovulatory 610 follicle (POF) cohort and two POF cohorts are also shown.

611

\begin{tabular}{|c|c|c|c|c|c|c|c|c|c|}
\hline $\begin{array}{c}\text { Sampling } \\
\text { date }\end{array}$ & $\begin{array}{c}\text { Sampling } \\
\text { site }\end{array}$ & $\mathbf{N}_{\text {his }}$ & $\mathbf{N}_{\mathrm{wm}}$ & $L$ range & $\begin{array}{c}\text { Pre- } \\
\text { spawners } \\
(\%)\end{array}$ & $\begin{array}{c}\text { Active } \\
\text { spawners } \\
(\%)\end{array}$ & $\begin{array}{c}\text { Spent } \\
(\%)\end{array}$ & $\begin{array}{c}1 \text { POF } \\
\text { cohort } \\
(\%)\end{array}$ & $\begin{array}{c}2 \text { POF } \\
\text { cohorts } \\
(\%)\end{array}$ \\
\hline $27 / 4$ & FR & 1 & & 282 & 100 & & & & \\
\hline $28 / 4$ & WF & 7 & 7 & $256-279$ & 57.1 & 42.9 & & 42.9 & \\
\hline $1 / 5$ & FR & 4 & 4 & $233-278$ & 25 & 75 & & 75 & \\
\hline $2 / 5$ & WL & 2 & 2 & $271-284$ & 100 & & & & \\
\hline $7 / 5$ & WF & 17 & 12 & $231-288$ & 11.1 & 88.9 & & 77.8 & 11.1 \\
\hline $8 / 5$ & FR & 13 & 8 & $239-293$ & 15.4 & 84.6 & & 61.5 & 23.1 \\
\hline $9 / 5$ & WL & 16 & 9 & $235-289$ & 43.8 & 56.2 & & 50 & 6.2 \\
\hline $10 / 5$ & $E F$ & 6 & 2 & $231-268$ & 16.7 & 83.3 & & 83.3 & \\
\hline $14 / 5$ & WF & 13 & 4 & $240-287$ & 38.5 & 61.5 & & 61.5 & \\
\hline $24 / 5$ & $E F$ & 2 & 2 & $241-259$ & 50 & 50 & & 50 & \\
\hline $28 / 5$ & WF & 29 & 13 & $240-291$ & 20.7 & 75.9 & 3.4 & 51.7 & 27.6 \\
\hline $29 / 5$ & FR & 15 & 10 & $242-290$ & 13.3 & 86.7 & & 80 & 6.7 \\
\hline $30 / 5$ & WL & 5 & 4 & $227-289$ & & 100 & & 100 & \\
\hline $31 / 5$ & $E F$ & 3 & 1 & $231-264$ & & 100 & & 66.7 & 33.3 \\
\hline $4 / 6$ & WF & 6 & 1 & $236-245$ & 33.3 & 66.7 & & 66.7 & \\
\hline $5 / 6$ & $\mathrm{FR}$ & 11 & 5 & $234-274$ & 36.4 & 54.5 & 9.1 & 54.5 & 9.1 \\
\hline $19 / 6$ & FR & 2 & 1 & $226-230$ & & 100 & & 100 & \\
\hline $20 / 6$ & WL & 7 & 3 & $229-265$ & & 100 & & 100 & \\
\hline $21 / 6$ & $\mathrm{EF}$ & 1 & 1 & 273 & & 100 & & 100 & \\
\hline $27 / 6$ & WL & 3 & 2 & $230-273$ & 66.7 & 33.3 & & 33.3 & \\
\hline Total & & 164 & 91 & & & & & & \\
\hline
\end{tabular}

612

613

614 